\title{
NEW PSELAPHIDAE FROM NEW HAMPSHIRE (COLEOPTERA) ${ }^{1}$
}

\author{
By Donald S. Chandler \\ Department of Entomology, \\ University of New Hampshire, \\ Durham, NH 03824
}

Two species of undescribed Pselaphidae were discovered during a comparison of the fauna of an uncut and a 40 year-old forest. The species are described here to provide names for a forthcoming paper comparing the pselaphid fauna of these two sites. Holotypes were cleared, disarticulated, and mounted on slides in Canada Balsam. Both are placed in the Field Museum of Natural History, Chicago. All measurements of specimens are in millimeters.

I would like to thank certain individuals for the loan of specimens, greatly extending the known ranges of these two new species. The abbreviations used to indicate specimen deposition follows the individual's affiliation: Rickard Baranowski, Lund University, Sweden (RBC); J. Milton Campbell, Biosystematics Research Institute, Ottawa, Canada (CNCI); Michael A. Ivie, Montana State University, Bozeman (DZEC); and Alfred F. Newton, Jr., Field Museum of Natural History, Chicago (FMNH). Specimens otherwise lacking an indication of deposition are in the collections of the author and the University of New Hampshire. I would like to thank J. F. Burger and R. Marcel Reeves, University of New Hampshire, for reviewing the manuscript.

\section{Euplectus silvicolus n. sp.}

(Figs. 1-3)

Length 1.36-1.44. Head glabrous, punctures indistinct, vertex with arms of distinct U-shaped impression originating from nude vertexal foveae; mandibles with five teeth on inner margin, third

'Scientific Contribution Number 1413 from the New Hampshire Agricultural Experiment Station.

Manuscript received by the editor March 11, 1986. 

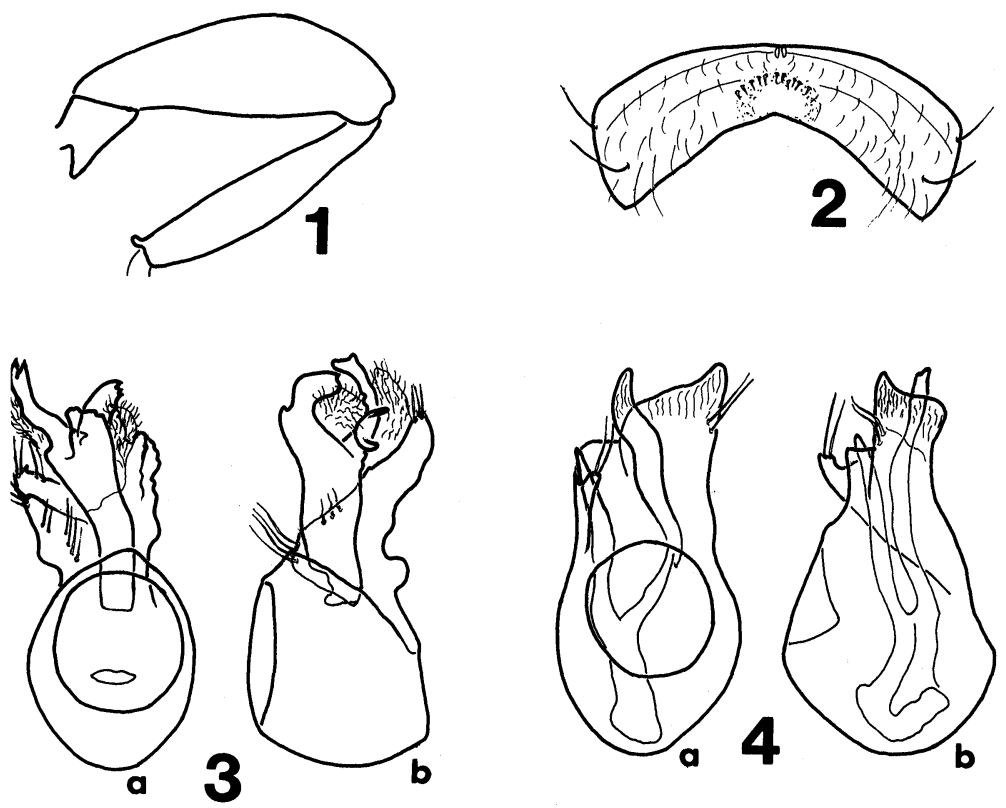

Figs. 1-3. Euplectus silvicolus n. sp., male. 1. ventral view last leg. 2. ventral view sternite VI. 3a. dorsal view aedeagus; $3 b$. left lateral view aedeagus.

Fig. 4. Actizona borealis n. sp., male aedeagus. a. dorsal view; b. left lateral view.

tooth largest. Elytra with four basal foveae. Tergites I-III with basal carinae, depressions between basal carinae only conspicuously setate on tergites I-II, I-III equal in length, IV half again as long as III.

Males with small spur at apices of all tibiae, metatrochanters at base with large medially directed spur; sternites IV-V simple, convex medially, VI obscurely depressed at middle, short aciculate setae in depression forming arc, division of sternite VII arcuate to left.

Females lacking spurs of tibiae and metatrochanters; sternites evenly convex.

Specimens examined, 27. HOLOTYPE male, New Hampshire, Carroll Co., The Bowl, 2.5 mi NW Wonalancet, VIII-6-1985, D. S. 
Chandler, sift conifer logs. PARATYPES: 1 male, 1 female, same data except IX-1-1984; 1 male, same data except VIII-21-1985; 6 males, 10 females, same data except VI-8/14-1984 (2), VI-15/201984 (1), VI-28/VII-4-1984 (1), VIII-2/ 10-1984 (2), VIII-11 / 16-1984 (1), V-23/VI-4-1985 (1), VII-2/10-1985 (6), VII-24/30-1985 (1), VIII-22/28-1985 (1), flight intercept trap; 1 male, $1 \mathrm{mi} \mathrm{N}$ Wonalancet, East Fork Spring Brook, 1900', VII-23-1985, D. S. Chandler, sift hemlock logs; 1 male, 1 female, same data except VII-2/10-1985, VII-31/ VIII-6-1985, flight intercept trap. Coos Co.: Norton Pool, 2 mi E East Inlet Dam, IX-7-1984, D. S. Chandler, sift rotten spruce/fir logs. Canada: Nova Scotia: 1 male, Cape Breton Highlands National Park, MacKenzie Mountain, PG648868, VII-4-1983, R. Vockeroth, pan traps (CNCI); 1 female, same data except Lone Shieling, PG729861, VI-25-1983, Y. Bousquet, pans (CNCI).

Biology: This uncommon species was only found in rotten conifer logs in an extensive litter survey at The Bowl. Most specimens were collected by flight intercept traps.

Discussion: This species is quite distinct among the Nearctic species of Euplectus by the presence of basal carinae on tergite III, spur of the male metatrochanters, simple sternites IV-VI, and smooth vertexal area. Since two species of Euplectus have been introduced to North America from Europe, the major faunal works of Jeannel (1950) for France and Besuchet (1974) for Central Europe were checked to be certain this species had not been previously described. In Wagner's (1975) recent revision of the Nearctic species of Euplectus, this species would be placed in the californicus-group. Silvicolus may be separated at couplet 5 of Wagner's key by the lack of any papilliform setae in the depression of sternite VI. This species differs from the generic diagnosis of Grigarick and Schuster (1980) in possessing basal carinae on tergite III, which are lacking in all other Nearctic species and also in the twenty Palearctic species in my collection.

Actizona borealis $\mathrm{n}$. sp.

(Fig. 4)

Length 1.20-1.32. Head with pubescent vertexal foveae, penultimate antennomeres symmetrical, antennal club with parallel margins, twice as long as wide. Elytra with three basal foveae. 
Promesocoxal foveae present, metasternal foveae separated by over two foveal diameters. Tergite lengths subequal, I-II with faint short basal carinae.

Males with protrochanters angulate on posterior margin, protibiae with small preapical spur; mesotrochanters posteriorly angulate, apical spur on inner margin of mesotibiae; sternites II-III with small setate tubercle near postero-lateral margins, VI simple, VII oval and setae over surface.

Females lacking spurs of tibiae and trochanters, lacking tubercles of sternites II-III.

Specimens examined, 8. HOLOTYPE male, New Hampshire, Coos Co., Jefferson Notch, 910 m, VII-14/31-1982, A. Newton \& M. Thayer, window trap. PARATYPES: New Hampshire: Carroll Co.: 2 males, 2 mi NW Wonalancet, VI-8/14-1984, VI-15/20-1984, D. S. Chandler, window trap; 1 male, The Bowl, $2.5 \mathrm{mi} \mathrm{NW}$ Wonalancet, VIII-16-1984, sift rotten wood; 1 female, same data except XI-23-1984, R. M. Reeves, sift birch stump; 1 male, same data except, VII-23-1985, D. S. Chandler, sift rotten beech logs. Canada: British Columbia: 1 male, Princeton, South Wash Creek, VII-22-1983, Lindgren funnel trap (DZEC); 1 male, Monashee Mountain near Cherryville, 1400-1600 m, VIII-12-1982, R. Baranowski (RBC), sifting litter and moss in spruce forest.

Biology: Collected in rotten beech and birch logs in uncut forests in New Hampshire.

Discussion: This species is very similar to Actizona chuskae Chandler from Arizona (Chandler 1985) in appearance and male characters. The genitalic form of borealis is identical in the British Columbia and New Hampshire specimens, and differs from that of chuskae in the form of the apex and internal spines of the aedeagus. These genitalic differences and the pubescent vertexal foveae of borealis readily separate the two species.

\section{SUMMARY}

Two undescribed species of Pselaphidae, Euplectus silvicolus n. sp. and Actizona borealis n. sp., were discovered during a faunal comparison of the forest floor Coleoptera of cut and uncut forests in New Hampshire. 
Literature Cited

BESUCHET, C.

1974. 24. Familie: Pselaphidae, pp. 305-362. In: Die Kaefer Mitteleuropas. Band 5, Staphylinidae II (Hypocyphtinae and Aleocharinae), Pselaphidae, 381 pp. Eds. H. Freude, K. W. Harde, and G. A. Lohse. Goecke \& Evers, Krefeld.

Chandler, D. S.

1985. The Euplectini of Arizona (Coleoptera: Pselaphidae). Entomography 3: 107-126.

Grigarick, A. A. AND R. O. SChUSTER.

1980. Discrimination of genera of Euplectini of North and Central America (Coleoptera: Pselaphidae). Univ. Calif. Publs Ent. 87: vi + 56 pp., 79 plates.

JEANNEL, R.

1950. Coleopteres Pselaphides. Faune Fr. 53: iii +421 pp. WAGNer, J. A.

1975. Review of the genera Euplectus, Pycnoplectus, Leptoplectus, and Acolonia (Coleoptera: Pselaphidae) including Nearctic species north of Mexico. Entomologica am. 49: 125-207. 

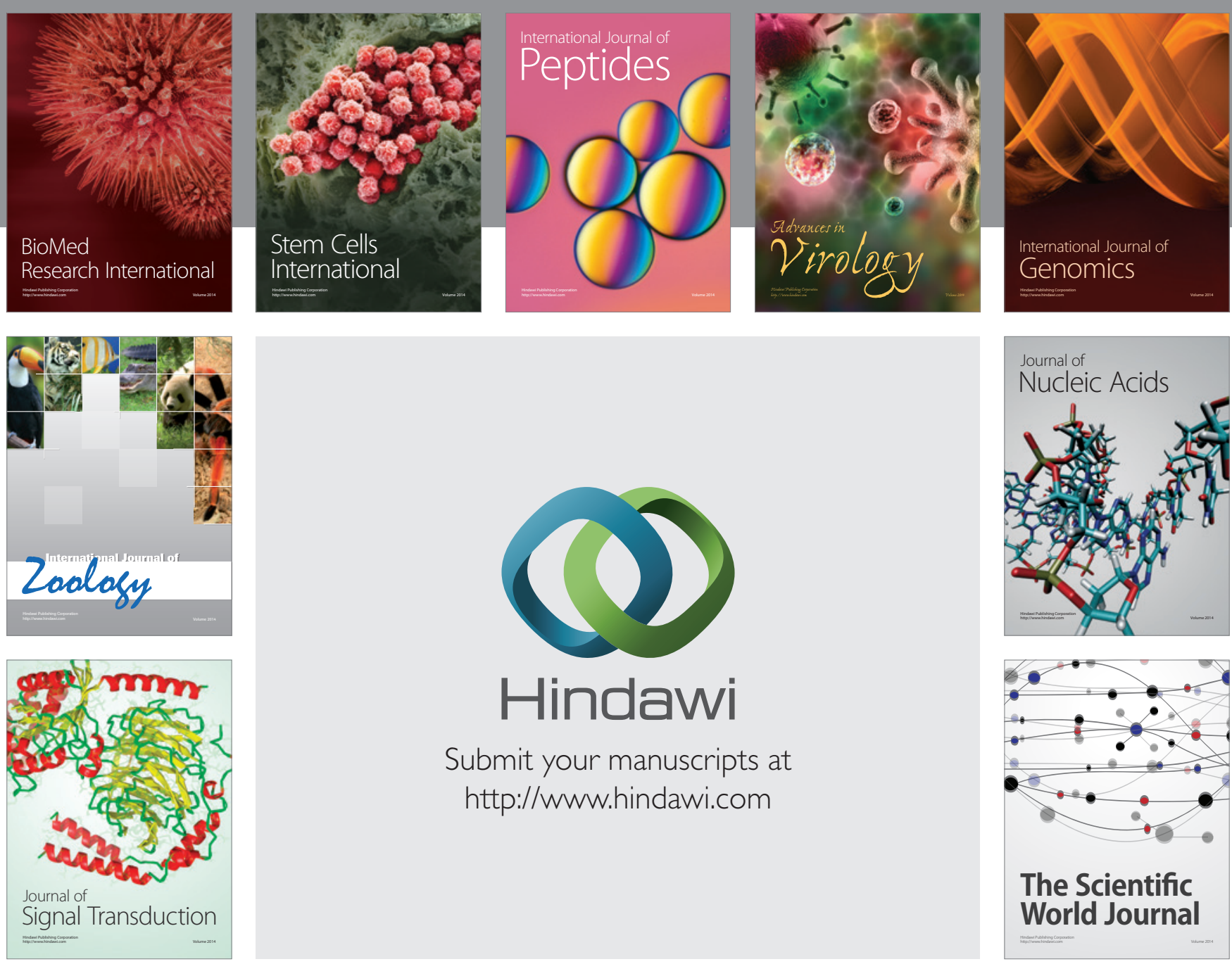

Submit your manuscripts at

http://www.hindawi.com
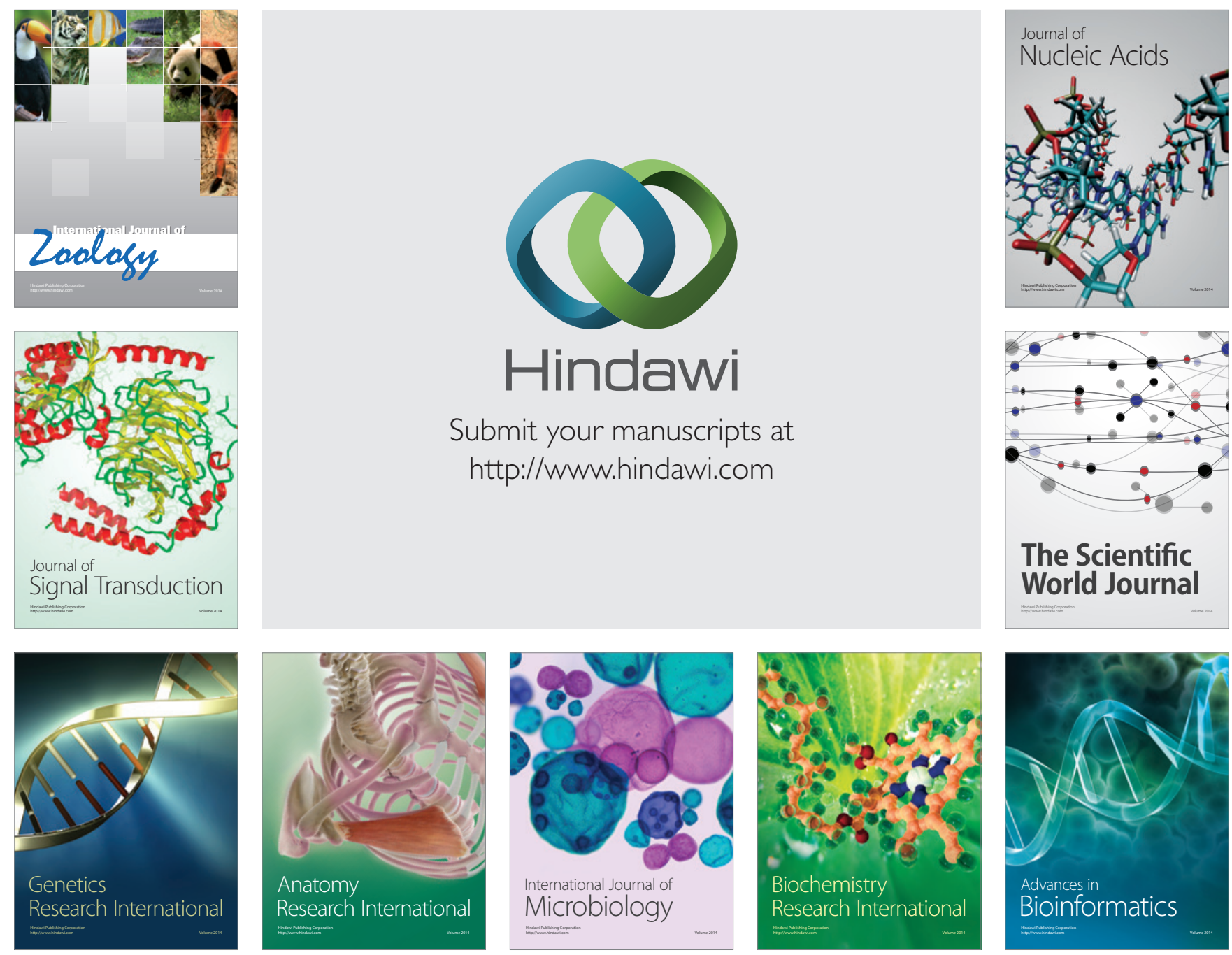

The Scientific World Journal
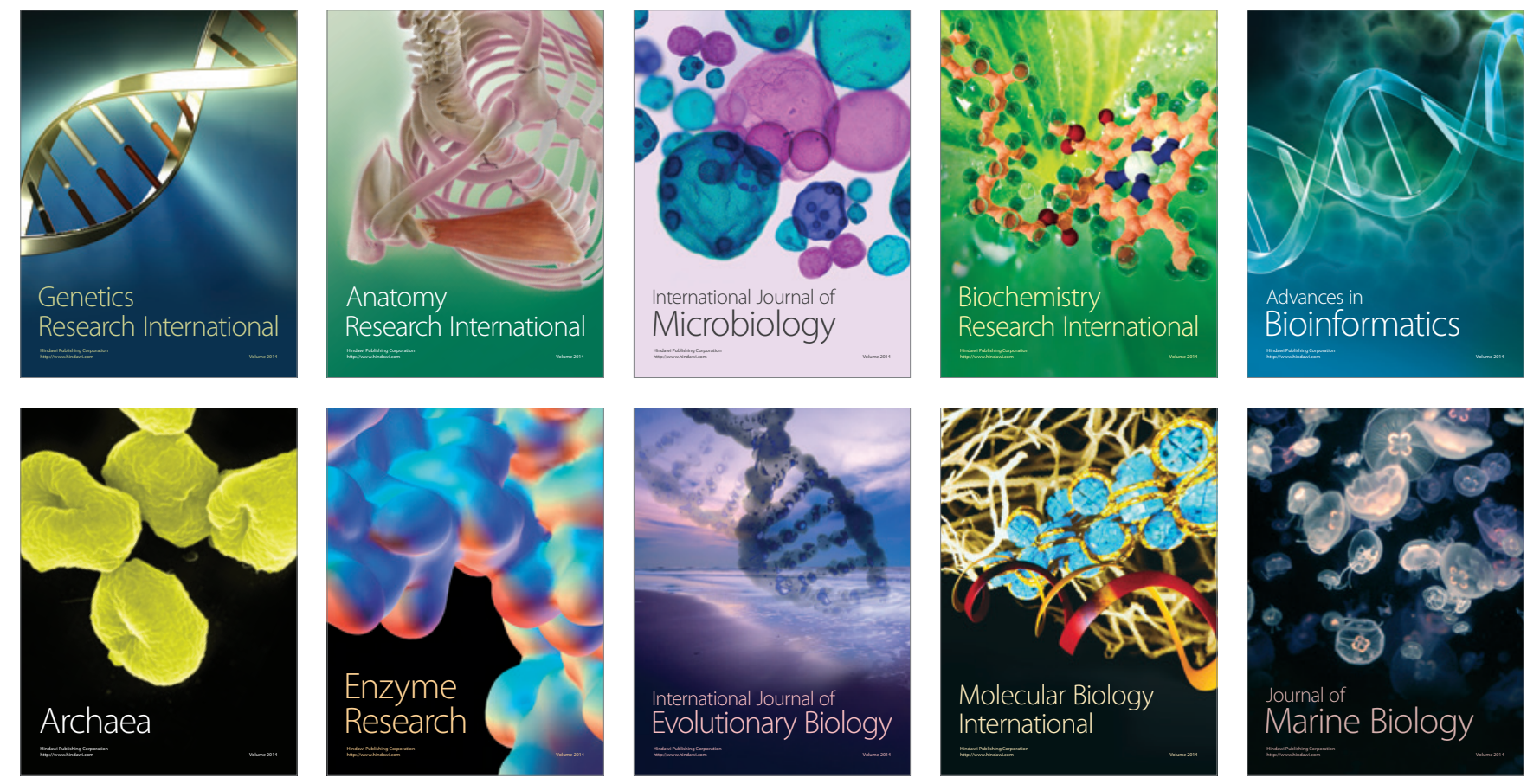